\title{
Differential Localization of Gossypitrin and Herbacitrin in Equisetum Sporelings
}

\author{
Singo Nakazawa and Kaoru Hanaya \\ Department of Biology, Yamagata University, Yamagata, 990 Japan \\ and \\ Research Institute for Science Education, Miyagi University of \\ Education, Aramaki-Aoba, Sendai, 980 Japan
}

Received August 1, 1983

The senior author noticed that the inside of the young sporeling of Equisetum arvense turned yellow when immersed in an alkaline soltion, and that the coloration was always restricted to the basal cell of the young protonema. The colored matter was extracted naturally into the alkaline medium, and the crude extract was examined with a spectrophotometer. As a result, it was tentatively considered to contain a kind of flavonoid. Later, it was chemically purified by the junior author and was identified to consist of two substances, gossypitrin and herbacitrin, as reported in this paper.

\section{Material and method}

Fresh spores of Equisetum arvense L. were collected in Yamagata as the material and were stored in a refrigerator under dried conditions at about $-5^{\circ} \mathrm{C}$. The spores were taken out according to demand of the experiments, washed by shaking in distilled water for about 1 minute, then they were sown in Knop's medium diluted to $1 / 5$ of the standard concentration, contained in petri dishes. The depth of the culture medium was about $3 \mathrm{~mm}$, the density of the spores was about 5 individuals for $1 \mathrm{~mm}^{2}$, temperature was about $20^{\circ} \mathrm{C}$, under constant illumination of white light at 1000 lux by use of $40 \mathrm{w}$ fluorescent tubes. Under these conditions, the spores sank to the bottom of the dish and germinated well. $0.1 \mathrm{M} \mathrm{KOH}$ water solution was prepared for the test of coloration.

For chemical examinaton, the dried spores ( $500 \mathrm{~g}$ ) were extracted for two weeks with acetone at room temperature, then the solution (A) and the residue were separated. The residue was then extracted with methanol (Soxlet) for $48 \mathrm{hr}$, and the methanol solution was separated from the residue (B). The methanolic extracts were concentrated to a small volume, to which was added ether. The etherial layer (C) was separated from the insoluble brown solid (D) by decantation. Finally the brown solid (D) was analyzed into further constituents in paper chromatography by use of Toyo Roshi No. 5 paper in n-BuOH-AcOH- $\mathrm{H}_{2} \mathrm{O}(4: 1: 2)$, and the constituents were examined of their fluorescence and were detected with $\mathrm{Pb}(\mathrm{OAc})_{2}$.

As the second method of chemical examination, the above fraction (D) was column-chromatographed on a cellulose microcrystalline (Merck, Art 2331) using $0.3 \%$ HOAc-sat. $\mathrm{H}_{2} \mathrm{O} \cdot \mathrm{AcOEt}$ as the solvent. In both methods, two pure substances 
were obtained, $1.45 \mathrm{~g}(0.29 \%)(\mathrm{E})$ and $0.55 \mathrm{~g}(0.11 \%)(\mathrm{F})$ respectively, and they were examined of their m.p., UV spectra in $95 \%$ ethanol, Rf value, and IR spectra.

The substances purified as above were commpared with authentic samples of gossypitrin and herbacitrin. UV spectra were measured using a Hitachi EPS-3T spectrometer. IR spectra were determined on $\mathrm{KBr}$ disks using a Hitachi 215 grating infrared spectrometer.

\section{Results}

Spores washed with distilled water were mounted on a glass slide with a drop of distilled water, observed under a microscope, then a drop of $0.1 \mathrm{M} \mathrm{KOH}$ solution was added. Suddenly the

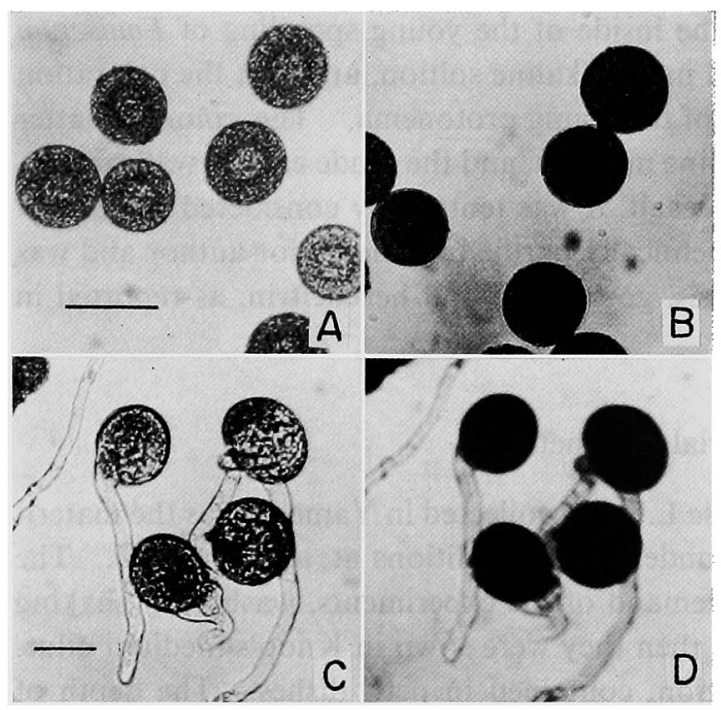

Fig. 1. Spores and sporelings of Equisetum arvense. A, fresh spores. B, the same with $\mathrm{KOH}$ displaying yellow coloration which shows presence of gossypitrin and herbacitrin. $\mathrm{C}$, sporelings consisting of a rhizoid and the initial cell of protonema. D, the same with $\mathrm{KOH}$. Scales represent $50 \mu \mathrm{m}$. cytoplasm of the spore turned yellow (Figs. 1A, B), then the coloration moved to the medium around the spore, and the spore lost the yellow color. This shows that the fresh spore contained a substance or substances colored yellow with alkali and the substance(s) naturally diffused out into the medium.

Fresh spores well germinated in Knop's medium in $10 \mathrm{hr}$, and they were divided into two cells, the rhizoid and the initial cell of protonema. At this stage, by addition of $\mathrm{KOH}$ solution, the yellow coloration appeared in the initial cell of protonema uniformly (Figs. 1C, D). Next $10 \mathrm{hr}$ later, the initial cell of protonema was divided into two, one of which began to elongate as the apical cell, but the other remained in quiescence as the basal cell. At this stage, the coloration by $\mathrm{KOH}$ occurred only in the basal cell. After the protonema developed to 3and 4-cell stages, also the coloration with $\mathrm{KOH}$ was observed only in the basal cell (Figs. 2A, B, C, D). In later stages, gradually, even the basal cell lost this special characteristic.

Fresh spores were centrifuged at $50,000 \mathrm{~g}$ for 3 minutes, which resulted in stratification of the intracellular materials. Lipid lalyer came to the centripetal end, then the layer of chloroplasts involving the nucleus, followed by the hyaline layer of cytoplasm, and finally mitochondria gathered at the centrifugal. Examination of the centrifuged spores with $\mathrm{KOH}$ solution revealed that the yellow coloration appeared most remarkably in the centripetal region containing lipid and chloroplasts. 
Fresh spores $(0.1 \mathrm{~g})$, after being washed repeatedly with distilled water, were immersed in $20 \mathrm{ml}$ of $0.1 \mathrm{M} \mathrm{KOH}$ solution, and the yellow-colored matter was extracted into the medium. The medium containing the colored matter was put into quartz cells, and examined by use of a spectrophotometer. The UV spectrum of this solution showed a characteristic absorption peak at around $260 \mathrm{~nm}$. The same measurements were also carried out with pure gossypitrin and herbacitrin separately dissoved in $0.1 \mathrm{M} \mathrm{KOH}$ solution. It was found that the absorption peaks at around $260 \mathrm{~nm}$ of the both compounds were quite similar to the spore.

The final fraction (D), obtained by extraction with methanol of the fresh spores, was examined by the junior author. The components (E) and (F) were identified as gossypitrin and herbacitrin respectively by comparing their m.p., IR (Fig. 3) and UV spectra with authentic samples. $\mathrm{UV}_{\lambda \max }^{\mathrm{EtOH}} \mathrm{nm}(\log \varepsilon):(\mathrm{E}) 261$ (4.14), 286 (3.98), 347 (3.93), 388 (3.96); (F) $226(2.76), 252(2.75), 273$ (2.80), 335 (2.68), 277 (2.71); m.p. (dp): $225^{\circ} \mathrm{C}$, (F) $233-236^{\circ} \mathrm{C}$; RF value: (E) $0.34,(\mathrm{~F}) 0.49$.

\section{Discussion}

Considered from the above experiments, it is clear that the spore of Equisetum arvense contains gossypitrin and herbacitrin. Therefore, the yellow coloration with $\mathrm{KOH}$ may be
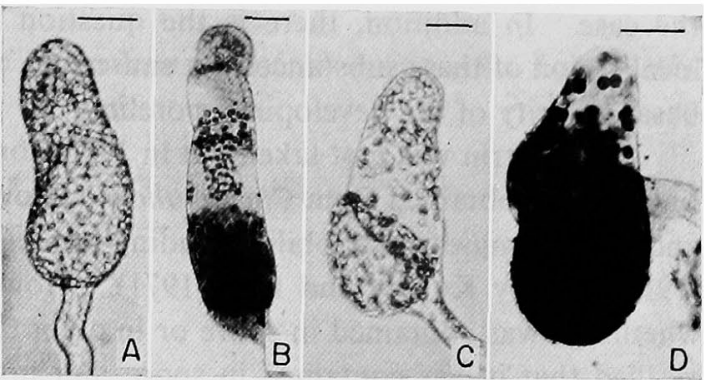

Fig. 2. A, C, two-celled protonema. B, D, the same with $\mathrm{KOH}$, Coloration is seen only in the basal cell. Scales represent $30 \mu \mathrm{m}$.
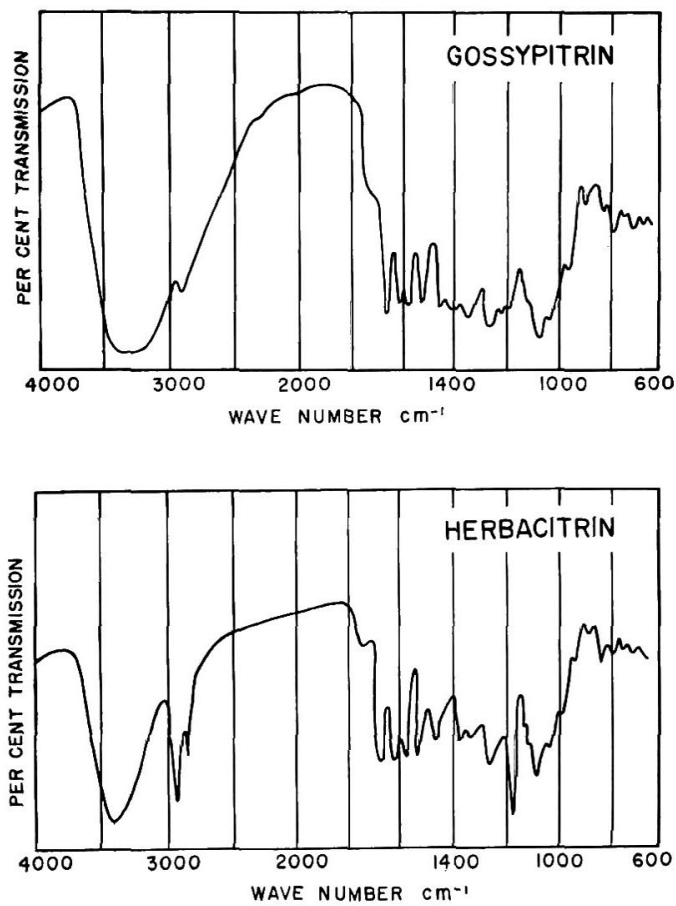

Fig. 3. IR absorption spectra of two substances, gossypitrin and herbacitrin, taken out of the Equisetum spore. attributed to these substances. They are uniformly distributed in the fresh spore. Later, after germination, they are contained mainly in the initial cell of protonema, and after that cell was divided into two, they are contained mainly in the basal cell, but little in the apical cell. As to this phenomenon, three possibilities are considered. The first is that gossypitrin 
and herbacitrin were translocated from the apical to the basal cell. The second is that they were changed to other substances in the apical, but remained unchanged in the basal cell. The third is that they diffused out of the apical cell into the medium, but did not in the basal cell. At present, it is not clear which possibility is the case. In addition, there is the question whether the apicobasally differential localization of these substances is a cause or a result of determination of the apicobasal polarity of the developing sporeling.

Gossypitrin was first taken out in 1916 from the flower of Gossypium by Parkin. Later it was obtained from Chrysanthemum flower by Geissman and Steelink (1957), and from Equisetum strobili including spores and other t:ssues by Nakabayashi (1957) and by Kutney and Hall (1971). However, in their reports, it is not clear whether it was contained in spore or in other tissues. In the present research it was verified that it was contained in spore, but not or hardly in other tissues. In addition, it was also clarified that the same spore contained herbacitrin. According to Nakazawa $(1978,1979)$, the rhizojd development of Fucus eggs and early development of sea urchin eggs are inhibited by gossypitrin at $10^{-3} \mathrm{M}$ in concentration. This implies that gossypitrin takes part in morphogenesis of Equisetum sporelings for differential regulation of cellular activities.

The authors express their cordial thanks to Professor Dr. T. Nakabayashi, Shizuoka University, for a gift of pure gossypitrin and herbacitrin samples, and also to Professor Dr. J. P. Kutney, the University of British Columbia of Canada, for a gift of authentic gossypitrin. Thanks are also due to Mr. K. Kono and Mr. K. Nishizuka for their assistance in experimental works. The present research was carried out in Yamagata University.

\section{Summary}

When the spore of Equisetum arvense is immersed in $0.1 \mathrm{M} \mathrm{KOH}$ solution, the cytoplasm is colored yellow, and the colored matter is naturally extracted into the medium. After germination, the same coloration with KOH takes place in the basal cell of protonema but not in the apical cell. The colorecd matter was taken out from the spore with aceton followed by methanol and ether, then it was analyzed by paper-chromatography and by column-chromatography. The analyzed components were separately examined by use of UV absoption and IR absorption spectometries. As a result, the colored matter was identified to be consisting of gossypitrin and herbacitrin. Role of these two substances in the cell of Equisetum is not clear, while presumed to take part in regulation of morphogenesis.

\section{References}

Geissman, T. A. and Steelink, C. 1957. Flavonoid petal constituents of Chrysanthemum segetum L. J. Org. Chem, 22: 946-948.

Kutney, J. B. and Hall, J. E. 1971. Constituents from Equisetum telmateia: the structure of equisporoside and equisporol. Phytochem. 10: 3287-3289.

Nakabayashi, T. 1957. Studies on the pigments of horsetail, spore-stalk of Equisetum arvense L. 
Part I. Isolation of two yellow glycoside pigments from horsetail. J. Agr. Chem. Soc. Japan 32: 436-439 (in Japanese).

Nakazawa, S. 1978. Notes on Fucales 10. Inhibition of rhizoid formation and cell division by gossypitrin in Fucus eggs. Jap. J. Phycol. 26: 5-7.

- 1979. Effects of gossypitrin on the development of sea urchin eggs. Bull. Yamagata Univ. Nat. Sci. 9: 609-612.

Parkin, A. G. 1916. The coloring matter of cotton flowers. Part III. J. Chem. Soc. London 109: $145-154$. 